\title{
Why Keep Silent Online? Voices from Stay-at-home Postgraduate Students
}

\author{
Xiaofeng Zhou ${ }^{1}$ \\ ${ }^{1}$ School of English Education, Guangdong University of Foreign Studies, Guangzhou, China \\ Correspondence: Xiaofeng Zhou, School of English Education, Guangdong University of Foreign Studies, 178, \\ Waihuan Donglu, Guangzhou Higher Education Mega Center, Guangzhou 510006, China.
}

Received: May 31, 2021

doi:10.11114/ijsss.v9i4.5249
Accepted: June 21, $2021 \quad$ Available online: June 25, 2021

URL: https://doi.org/10.11114/ijsss.v9i4.5249

\begin{abstract}
Online classroom silence is an overlooked site of research irrespective of the growing popularity of online teaching in today's education. Against this background, this study showcases why a group of postgraduate students keep silent in their online classes through classroom observation, stimulated recall interviews and in-depth interviews. Reasons found are classified into three categories: the peculiarity of online class, the uniqueness of postgraduate academic lesson, and other general reasons resembling the ones in the traditional classroom. In addition, these factors are found to be interconnected and sometimes exerting both positive and negative effects; unexpectedly, the factor of 'losing face', contrary to previous studies, is trivial in contributing to postgraduate students' online-classroom silence.
\end{abstract}

Keywords: silence, online classroom, postgraduate students

\section{Introduction}

The outbreak of Covid-2019 leaves nearly all students and teachers in China and even the whole world taking class online. Faced with such global health emergency, education has avoided being suspended via adopting computer-mediated online teaching. Online classroom, in this case, is of great significance. Besides, with the progress of technology and education, lecturing without space limitation is more extensively pursued. Online classroom is more frequently employed and is bound to be a popularity in education.

Silence is an indispensable aspect of instruction. Previous research on silence has focused on social and cultural phenomena of foreign students abroad (e.g., King, 2013; Liu, 2001; Hu \& Fell-Eisentkraft, 2003). Studies on ESL or EFL students in China have shown that their limited English language skills and ability to communicate among their peers and instructors was a major cause of classroom silence (Jackson, 2002; Liu \& Littlewood, 1997; Ping, 2010). However, most of these studies focus only on undergraduate students instead of students in other academic level; also, nearly all studies are conducted in the setting of traditional face-to-face classroom, but online classroom is barely explored.

Clearly, silence is not unique to face-to-face instruction; silence is also experienced in online communication (Zembylas $\&$ Vrasidas, 2005); and it is largely evaluated in terms of class participation (Bista, 2012). Teachers encourage their students to participate orally in class discussions and they also assign daily participation grades (Howard \& Henney, 1998). However, it has been pointed out that the existing literature on online education has neglected or oversimplified the role of silence; for example, silence has been merely linked with either non-participation or marginalization (Conrad, 2002; Daisley, 1996; Feenberg, 2001). To argue against this bias, many scholars has pointed out that silence sometimes also serves as a rich communicative resource in understanding the subject matter and as a power to motivate students' learning (Jaworski \& Sachdev, 1998; Lickerman, 2009; Armstrong, 2007). In light of these arguments, therefore, this study intends to identify the role of silence in online class by investigating three postgraduate students' silence in postgraduate level online classes.

\section{Literature Review}

\subsection{Definition of Classroom Silence}

"Classroom silence" is defined variously across different contexts. Scholars in China are more likely to view silence as a non-verbal state. For example, silence is defined as "the silent and non-fixed semantic non-verbal communication 
behaviors presented by teachers and students in the classroom teaching environment"(Liu, 2005, P.9). Qiao(2008) believed that students' silence in class is a kind of silent behavior, which represents their inability, unwillingness or avoidance. Teng (2009) also pointed out that silence in class is a psychological state and behavior of students, in which they are unwilling to speak up to participate in teaching activities.

However, this paper would like to distinguish "silence" from "non-verbal" in online classroom scenarios. "Non-verbal" refers to an objective state possessing no sound, which is always used interchangeably with 'silence' in the educational setting. However, in online classroom settings, interactions sometimes are achieved by "literal discussion". Many students tend to respond to teachers through the online function of "literal chatting", which requires no verbal response. Therefore, online classroom silence in this paper, based on definitions given by previous scholars, will be defined as 'no verbal nor literal response from students when teachers initiate an interaction.'

\subsection{Previous Studies on Classroom Silence}

Silence in the institutional setting was neglected since early years(Jaworski, 2005). Though overlooked, a majority of the studies on silence focus on English language teaching, basically among English as second language learners. Most studies related to ESL students show that students' limited English language skills and ability to communicate among their peers and instructors was a major underlying cause of classroom silence (Jackson, 2002; Liu \& Littlewood, 1997; Teng, 2009; Ping, 2010; Wu, 2019). Some research on Chinese students argue that they were intentionally silent in the classroom because they preferred less frequent participation and offered brief responses to avoid being labeled as a "show-off" to their Chinese peers (Liu \& Littlewood, 1997), or to avoid losing face in class (Pu, 2009). There are also studies highlight the contribution of external factors, for example, the Confucian cultural heritage, in which Chinese students experienced teacher-centered instruction and placed a great degree of respect on their teachers for their wisdom and knowledge(Spizzica,1997; Kirkbride, Tang \& Westwood, 1991; Carson \& Nelson, 1996), the reactions of professors and peer students in the classroom(Rachel Zhou, Knoke, \& Sakamoto, 2005), and the way teachers organize the class and ask questions(Chaudron, 1998; Tsui, 1996). Harumi (2010), however, tend to take a holistic perspective, maintains that at the roots of silence inside the EFL classrooms were linguistic factors (limited vocabulary, expression, grammar, etc.), psychological factors(shyness, boredom, lack of confidence, etc.), and socio-cultural factors (Confucian ethics, classroom atmosphere, etc.).

Though insightful, these studies are conducted in traditional face-to-face classroom settings. Online teachers often run into issues of nonparticipation and unresponsiveness of the online students (Beaudoin, 2002; Benfield, 2000; Jones, 1999; Zembylas \& Vrasidas, 2005). As aforementioned, the existing literature on online education has neglected or oversimplified the role of silence; for instance, silence has been merely linked with either non-participation or marginalization (Conrad, 2002; Daisley, 1996; Feenberg, 2001). In addition to the perception of silence as non-participation, silence in online occasions is also interpreted as a consequence of exclusion and silencing (Zembylas $\&$ Vrasidas, 2005). However, in spite of studies into online silence from different perspectives, few studies explore the reasons behind online classroom silence. An exception can be found in Kalman (2008), which revealed several categories of online classroom silence, shed some lights on the cause of online silence but did not explicitly investigate the specific reasons behind.

As the case in traditional classroom, the revelation of the variable reasons behind online silence is critical to enhancing the quality online teaching; whereas the silence phenomenon in online teaching is relatively underexplored. Based on the literature reviewed, the author contends that exploring the reasons underlying online classroom silence is essential and urgent in today's increasingly prosperous and indispensable online education.

\section{Methodology}

\subsection{Objective and Research Questions}

The participants of the present study are 3 postgraduate students in China who study in their first year of English Education. Due to the outbreak of Covid-2019, they all have been taking online class since the end of March of 2020. TengXun Class, TengXun Meeting, Raining Meeting as well as Zoom are the main online tools employed in their class. Both English and Chinese are used in their class, and English language dominates the classes. What makes the investigation available is that the author has established a rapport with these participants since early times. In addition, the author is able to be one of the attendants of the online class they've taken, which helps the author better collect and understand the data.

The reasons for selecting postgraduate level class in this study are, for one thing, postgraduate students is an ignored group in relevant research, and for another, postgraduate level class is often a place where intense communication is needed for academic purpose, which endows this research with sufficient 'class participation' moments. Through the observations of classroom sessions and stimulated retrospective accounts of the students as well as in-depth interview, 
the study intends to identify reasons for students' silence through the following two research questions:

1) What are the postgraduate students' perceptions about their silence in online class?

2) What are the reasons for the postgraduate students' silence in online class?

\subsection{Data Collection}

Three forms of data are collected, i.e., classroom observation, stimulated recall interview and in-depth interview. The purpose of online classroom observation is to provide a guidance for the following stimulated recall interview. The stimulated recall interview is conducted to access students' concurrent interpretations of their classroom performances especially their silence episodes, as a result of which the direct reasons for students' silence will be figured out. The final in-depth interview intends to obtain participant's overall perceptions over the silence phenomenon in online class, which enables the author get a deeper and broader understanding into the reasons behind and also make a supplement to the previous stimulated recall interview.

1) Online classroom observation and recording

The classes of the two courses taught by different teachers, namely Sociolinguistics and Textual analysis in English Education, are to be screen recorded through the recording app EV Recording. The screen recordings cover half of the lessons of the whole semester, which amounts to 14 classes, 21 hours in total. Based on the redefinition of online silence mentioned above, the author inspects the recordings right away after the class and weed out the ones that lack interactions or silence moments. Eventually there are only seven pieces of class recording lasting for 10.5 hours that are considered useful for the present research.

2) Stimulated recall interviews

Based on the class recordings as well as the classroom participation of the author herself, three participants are invited to have a stimulated recall interview with the author through phone call. To ensure the participant's fresh memory, each round of the interview is done within two days after they took the class. During the interview, the author encourages them to elaborate on their class participation experiences especially their silent moments. The questions focus on how they feel especially at their silent moments and why they keep silent in that particular class. Finally, seven rounds of stimulated interview for each participant ( 21 rounds in total) are conducted, each of which lasted no more than 20 minutes. All of the interviews are recorded and transcribed for further analysis.

3) In-depth interview

At the end of the semester, the participants are invited for a further in-depth interview through phone call, which lasts for 40-60 minutes for each participant. The aim is to figure out their overall perceptions about their performances in online classes during the whole semester, and silent moment again is emphasized during the interview. Therefore, in order to obtain a deeper communication with the participants, in this stage the interview questions are much broader designed and are sent to participants in advance. All of the interviews are recorded and transcribed for further analysis.

\subsection{Data Analysis}

\section{1) Transcription}

The recordings are transcribed through an online APP XunFeiTingJian. Then after the correcting of some errors and further confirmation from participants, the transcripts are modified and improved, which exceed 30,000 words. At last, these transcripts are renamed and numbered, in which the basic information including the interview time as well as participants' name and gender are included.

\section{2) Coding}

The first step is to read the transcripts extensively in order to obtain a general understanding of the participants' experiences and make notes about the author's first impression. In the subsequent careful readings, the author codes the words that explain why the participants keep silent or speak out in classes, the words repeated by the participants, and also the words that surprise the author or remind the author of something that appears in other research. Finally the transcripts are reread and the last step is repeated.

\section{3) Categorizing}

All the codes are listed in a blank paper and color-coded. In total 44 codes are concluded from the stimulated recall interviews and 120 codes are found out from the in-depth interview. Using the color-coded lists, the author looks for common issues and themes across the cases so as to group the issues into larger categories. Then each transcript is read again to compare and contrast the statements with the categories that emerged. In the end, nine themes subsuming to three broad categories are figured out. 


\section{Research Findings}

There are finally nine themes emerging from the data that help to interpret the reasons behind online classroom silence, which can be further classified from three different perspectives. These include aspects as 1) the peculiarity of online class, which includes the reasons as a) the mechanical organization of online class, b) the face-hiding feature of online class, and c) teachers' inexperience in taking online class; 2)the uniqueness of postgraduate academic lesson, including the reason as a)the degree of difficulty of the course content, b)student' commitment to their preview or preparation before the class, and c) students' sense of responsibility; 3) the general reasons as a)teachers' mode of teaching, b) the classroom atmosphere, and c)the personal capability of students.

\subsection{The Peculiarity of Online Class}

1) The mechanical organization of online class

Some of the participants seem to express their unsatisfaction toward the inconvenience of online interactions, which prevents them from initiatively posing questions in class and interacting with classmates. One of the participants, Robert (pseudonym), described his failed experience in trying to actively interacting in online class:

I used to propose questions in class whenever I felt confused or curious, I mean, in traditional face-to-face classroom. It was free to do so. Even sometimes when the professor saw a puzzled frown in my face he would ask me if I had any questions. However, in this semester's online class, I never did this unless the professor asked all of us if there were any questions and clicked the button of 'allowing hands-up' in the online teaching app. Never dare anyone opened his microphone and interrupted the professor and asked a question. (in-depth interview, July 31,2020 )

Being used to be an active member in traditional class but now a 'silent' student in online class, Robert hoped to return to the traditional face-to-face classroom. Specifically, the mechanical feature of online class can be attributed to the following points: a) the moments of interaction are mechanically preset by teachers, and students have no chance to initiate an interaction; b) online course obstructs interactions among students, and communication would not happen if it bothers to open a we-chat or some other online applications, which prevents students from actively thinking; c) if there is an interaction, it would just be an one-to-one conversation that not welcome others because it would make one look impolite and disrespectful; d) the accessibility of reviewing the class discourages students from proposing questions in class. When talking about the last point, another participant, Stacy (pseudonym) said:

Actually, many times I did have some confusions, but in thought of my screen recording of the class I would choose to keep silent and to review the recordings and figured the confusions out by myself after the class. (in-depth interview, July 31, 2020)

\section{2) The face-hiding feature of online class}

One of the most direct impacts exerted by the face-hiding feature of online class is that students would be easily distracted from class. When asked why they keep silent in certain class, many times the participants answered 'I just got lost' (stimulated recall interview, June 3, June 4, July 1, 2020). What's worse, being free from showing face in front of teachers, many of the participants told that they did not complete the assignments or preview the textbook as seriously as they did in traditional class. As a result, they performed inactively in class. Stacy said:

It was unavoidable to say that I was not that self-conscious in doing preparation work before class. What made me lazier was the notion that since the teacher did not know me and could not see my face, I would dodge a bullet. (in-depth interview, July 31, 2020)

Poor preview work, to a large extent, prevents students from active participation. It is highly related to the communication-oriented feature of postgraduate academic level lesson, which would be further explained in the following section. The point here is that the face-hiding feature of online class deteriorates the silence phenomenon by making students take chance to escape assignments or preview work that might be essential in next class. Similarly, in more than 4 rounds of the stimulated recall interview, when asked why the participants were silent in certain classes, nearly all of them told that 'I did not preview the textbook' or 'I did not complete the homework, so I did not dare to open my mouth' (stimulated recall interview, June 12, June 28, July 1, July 8, 2020).

However, another participant showed her preference for online class by praising its face-hiding feature. Emma(pseudonym) said:

Compared with face-to-face classroom, I preferred to speak in online class. You know, I was a little bit introverted, and hiding my face made me less nervous when I responded to teacher's questions. (in-depth interview, July 31, 2020)

It thus demonstrates that the face-hiding function of online class is not solely negative nor positive on the issue of 
classroom silence phenomenon. It depends on individuals.

3) Teachers' inexperience in taking online class

One of the unexpected points emphasized by some participants is the concern for teachers' unfamiliarity with the form of online class. As Robert reported:

Actually, many times we were not silent. We actually had made responses in a literal way. You know, there was a literally discussion area in the online classroom, but usually it was ignored by teachers, and when they notice the messages we posted, the time was over. Most of them seemed not familiar with the app. (in-depth interview, July 31, 2020)

In Robert's words, it is sometimes the teachers' lacking of experience in applying the online app that results in a false appearance of class silence that should have been avoided. Another participant, Emma(pseudonym), expressed similar opinion towards this issue:

Our teachers have been on their career for more than 10 or 20 years by taking face-to-face classes. It was the virus outbreak that forced them to try and accept a new form of class taking. So, it was unavoidable that they would imitate or even copy the traditional mode of teaching, for example, being teacher-centered. It was hard to make a change within a short semester. Let alone the teachers themselves were too busy to do so. (in-depth interview, July 31, 2020)

Teachers are ordered to take online class suddenly without any training or experience in it, and thus it is possible that teachers seldom redesign their teaching plan to fit into the form of online class. Specifically, teachers might not, intentionally, learn and make full use of the potential resources in online classroom to promote participation and interactions in class.

\subsection{The Uniqueness of Postgraduate Academic Lesson}

1) Difficulty of the course content

One of the participants, Emma, complained more than 5 times that the content of certain courses was too complicates for her to grasp. It seems that the difficulty of the courses constituted the main theme throughout her talking.

As I had mentioned, it was really hard for me to understand what teachers said in class unless I had already previewed the content extensively, I mean, more than 3 times of reviewing. What's worse was the case that the material itself was too professional to understand. It made me feel that teachers were flying in a very high knowledge level but I was still a toddler. I mean, being silent in class did not mean I did not want to make a sound but that I was just unable to do so. (in-depth interview, July 31, 2020)

Compared with undergraduate academic years, courses taught in postgraduate period are much more professional and academic. Students who have never treaded into the field of academic research would find it a little hard to follow. At this point, Stacy said:

Well, relatively I was not that silent in our Social Linguistics course. It was not as incomprehensible as other courses, instead, it was quite close to our daily life. Linguistic phenomenon that introduced in the class actually were what we frequently met with, so it was not difficult to make a response in class (in-depth interview, July 31 , 2020)

These responses suggest that the difficulty of the course does exert impact on students' capability to participate in class interaction. However, it is interesting to find that in stimulated recall interviews, when asked why they did not make a response towards teachers' questions, most of their responses were that 'I did not preview the textbook' or 'I did not preview the article assigned' (stimulated recall interview, June 12, June 28, July 1, July 8 , 2020) instead of complaining the incomprehensibility of the class. Therefore, it suggests that, to some extent, the degree of the difficulty of the course depends part on students' own commitment to their preview or preparation work before class. It will be discussed in detail in the following section.

2) Students' commitment to their preview or preparation before the class

As mentioned above, in stimulated recall interviews, all participants told many times that the direct reason why they made no response in class was that their poor preview work unenabled them to do so. In the final in-depth interview, when talking about this issue, Stacy explained:

I admitted that most of the time I did not respond to teachers was just because of my ill-preparation, but I did not mean to. Every week I felt overwhelmed by different assignments from different courses. I got 8 different courses to take this semester and nearly every week all of them would leave some assignments. I was too exhausted to finish them all, so I just tried to complete the relatively more important ones. For example, the 
ones would be checked or the ones that demanded us to share in class (in-depth interview, July 31, 2020)

It suggests that the poor preview work influences students' class participation. For one reason, it is the arduous tasks that discourage them from sparing times to do preview. For another, compared with preview assignment, students would like to pay more attention to other homework that are higher demanded.

\section{3) Students' sense of responsibility}

The participants are well aware of their different 'identities' in class, which arouses or weakens their sense of responsibility to break classroom silence. For example, Stacy, when asked why she participated much more actively in one certain course than any other classes, responded:

That was because the teacher of that course was my supervisor. When she initiated an interaction activity but no one responded, I felt obliged to break the silence. Most of the time I would try my best to do so, otherwise it would make me look irresponsible. (in-depth interview, July 31, 2020)

In postgraduate academic level, each student will be matched with a supervisor who assumes the duty of guiding the student in their academy. They usually get a rapport with each other out of class. In Stacy's case, it is the very rapport with supervisor that encourages her to break silence in class. Another participant, Emma, also gave a similar response toward the same issue:

I was ordered to be a course monitor. I had to make some responses even if I did not know the right answer. I got to do my own job! (in-depth interview, July 31, 2020)

Those two participants get their own special identities in different courses, which endows them with special responsibilities --- to break silence in class. However, there is also another case, and that is the same participant, Stacy, said:

Well, in other courses, I never felt embarrassed if the whole class kept silent. Since no one stands out and make a response, why me? (in-depth interview, July 31, 2020)

It thus implies that the sense of responsibility also has double sides, which on the one hand urges students to break a silence and on the other impede them to do so.

\subsection{The General Reasons}

\section{1) The classroom atmosphere}

The whole classroom atmosphere can be both lively and dreary, which is a potential factor influencing students' individual performance in class. When it comes to this issue, Robert responded:

I definitely chose to be silent when there was no one to make a sound. I didn't want to be different. It would make me feel embarrassed. (in-depth interview, July 31, 2020)

Trying to be gregarious, this participant makes himself 'fit into' the silent classroom atmosphere. Whereas another participant, Emma, gave a polar opposite answer:

I did not like an embarrassing classroom atmosphere. Every time teachers proposed a question and no one responded, I felt I got the duty to change this situation. I used to be a teacher myself, I knew what that felt like when nobody in my class responded to me. It was disappointing, actually. (in-depth interview, July 31, 2020)

These statements reveal the double roles that the overall classroom atmosphere plays -- both fostering and impeding classroom silence. It depends on individual class members to 'fit into' the classroom atmosphere or to be the one standing out.

\section{2) Teachers' mode of teaching}

The participants seem to be active in some classes but relatively silent in some others. Except for the reasons revealed above, such as the difficulty of the course content and students' own sense of responsibility, participants also share their opinions towards teachers' different modes of teaching. Robert said:

Honestly, some classes appeared to be too dreary to initiate an interaction, but there were also classes in which teachers intentionally design various forms of interaction, which not only included interaction between teachers and students, but also the ones between students and students as well as students and the course content. For example, firstly the teacher might divide us into several online groups and discussed about a problem, and afterwards she would pick one student from each group to share opinions and interact with the student, and at the same time members from the same group could also talk freely. I like this mode of learning and I always actively participated in. (in-depth interview, July 31, 2020)

It quite obvious that teachers' mode of teaching affects students' motivation of participation. More interactions designed, 
more participation motivated, and as a result, less silence produced.

3) The capability of students

The participants sometimes use silence as a protection strategy in cases where they felt their language abilities and content knowledge were insufficient to express themselves clearly. Emma said:

You sometimes could not say what you really wanted to say. It sounded incomplete, and you didn't want your peers 'hanging in the air'. You started talking; these people kept waiting for you hoping that they would get something out of it. Then you just couldn't talk ... Starting a comment which you won't be able to finish was I thought sabotaging something that went just fine. (in-depth interview, July 31, 2020)

Similarly, some participants reported remaining silent in cases where they perceived that their questions or comments were not 'significantly important'. Heavily influenced by the belief that students expose their intelligence or ignorance to the teachers through their posting of questions, participants frequently use their silence as a method to avoid exposing themselves. Just as Stacy reported:

Sometimes I did have something confusing me when teachers asked if we had any questions, but being afraid of exposing my distraction or my ignorance, I always kept silent and let my confusions gone with the wind. (in-depth interview, July 31, 2020)

\section{Discussion}

From both stimulated recall interviews and in-depth interviews, 3 categories of reasons, including 9 factors in total, are extracted to be helpful to interpret the reasons behind postgraduate online classroom silence. Based on the research findings, some insights are-as follows:

Firstly, it's hard to define some of the factors definitely as causing or helping break the online classroom silence. Some of them play double roles. According to Kalman (2008), silence is a subjective experience, which is highly contextual and individual dependent, making silence a complex issue to observe. In this study, as showed above, factors as the face-hiding feature of online class, students' sense of responsibility as well as the classroom atmosphere all have double sides --- either causing or preventing online classroom silence. For example, as for the factor of classroom atmosphere, previous studies argue that students tend to follow the whole class when it comes a hesitation between keeping silent or making a response (Harumi, 2010; Rachel Zhou et al., 2005); whereas in this study a silent classroom atmosphere proves to be effective in bringing about silence and stimulating students to break it.

Secondly, the factors extracted are actually interrelated with each other, each of which cannot be separated as a single factor that causes or prevents online classroom silence. For example, as aforementioned, teachers who used to teach in traditional face-to-face class are unskilled in taking an online class, therefore both the factors of teachers' inexperience in taking online class and the mechanical organization of online class have great impact on teachers' mode of teaching. However, teachers who intentionally design their class with many interactions are more likely to create an active classroom atmosphere, therefore, teachers' mode of teaching will in a step further influences the whole classroom atmosphere, which sometimes inspires or prevents students' sense of responsibility to break silence. Similarly, as showed in the last section, the face-hiding feature of online class sometimes makes students take chances to escape from their preview homework, and this will make the students lag behind in understanding the course content. As a result, they will be incapable of actively participating in class. That is how the factors of the face-hiding feature of online class, students' commitment to their preview work, the difficulty of the course content and students' capability are interrelated with each other. The complete interconnections are presented in the following Figure 1. 


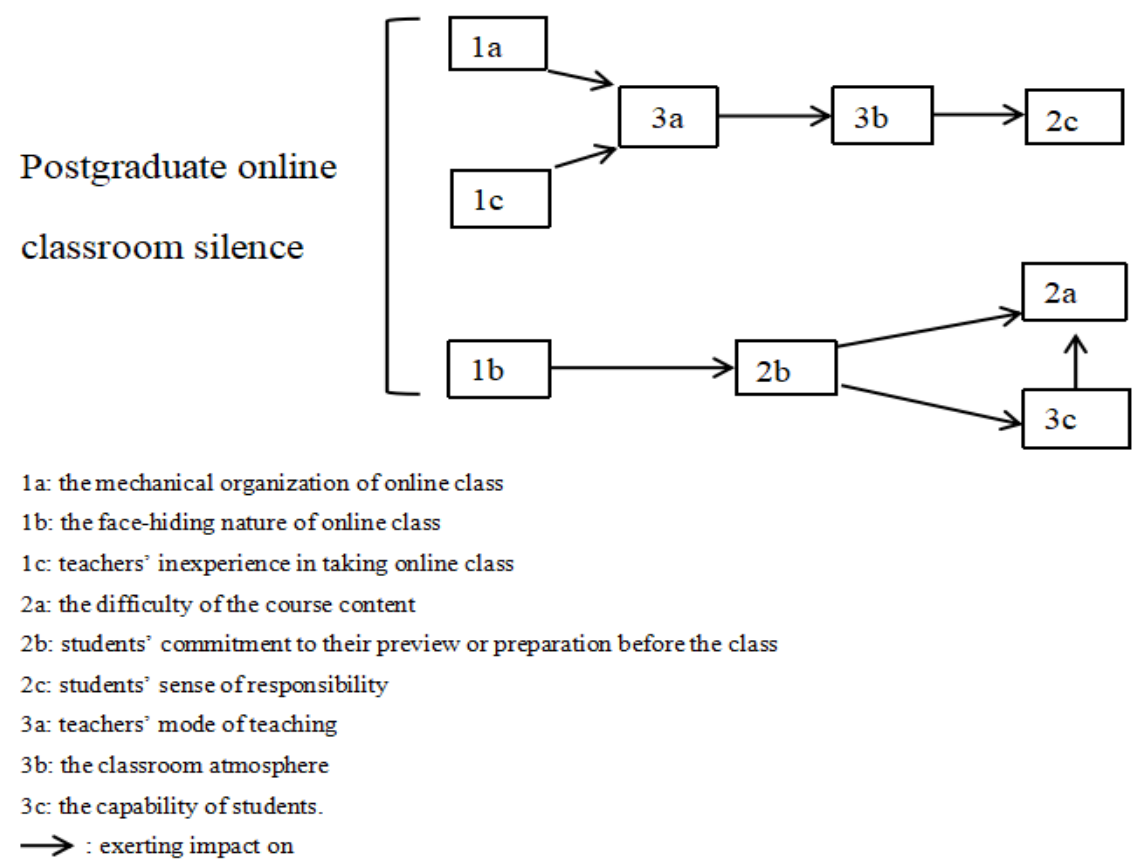

Figure 1. The interconnections between silence factors

Thirdly, in this study, the three factors, namely, classroom atmosphere, teachers' mode of teaching and students' capability are categorized as 'the general reasons' for the fact that they coincide with what have been found in previous research on traditional classroom silence (e.g., Carson \& Nelson, 1996: Chaudron, 1998; Jackson, 2002; Kirkbride et al., 1991; Tsui, 1996; Liu \& Littlewood 1997; Ping, 2010; Rachel Zhou et al., 2005). It suggests that no matter being online or face-to-face, the three essential components constituting a class, namely the classroom, the teacher as well as the students, always play a role in classroom silence, negatively or positively.

Lastly, one another interesting finding that deserves to be pointed out is that being afraid of losing face, in this study, never drives students to keep silent. "Face" is always a concern in the way students are expected to behave in Chinese classrooms. Proved by previous studies, the concern about "face" tends to cause many Chinese students to sit silently in classrooms (Jin \& Cortazzi, 2006; Pu, 2009; Wen \& Clement, 2010). Nevertheless, in this study, none of the participants mentioned about losing face in 21 rounds of stimulated recall interview, and when asked in the final in-depth interviews, they all showed no care for "face". The reasons behind might be, one the one hand, students in 21-century tend to be more and more affected by an open and multi-cultural education environment, and, on the other hand, taking class online makes them more confident in speaking and interacting in class (Daisley, 1996).

\section{Conclusion}

Drawing on the approach of classroom observation, stimulated recall interview and in-depth interview, this study sheds light on how to interpret postgraduate students' silence in online classroom. Specifically, nines reasons from three categories are found to contribute to online classroom silence, which are 1) the peculiarity of online class, which includes the reasons as a) the mechanical organization of online class, b) the face-hiding feature of online class, and c) teachers' inexperience in taking online class; 2)the uniqueness of postgraduate academic lesson, including the reasons as a)the difficulty of the course content, b)students' commitment to their preview or preparation before the class, and c) students' sense of responsibility; and 3) the general reasons as a)teachers' mode of teaching, b) the classroom atmosphere, and c)the capability of students. What more, these factors are found to be sometimes double-edged and always interconnected; general factors, namely, classroom atmosphere, teachers' mode of teaching and students' capability, are found to be influential in both traditional and online class; concerning for losing face, however, is found to be neglectable when explaining online classroom silence.

This study is not without limitations. Firstly, the findings drawn from the analysis of three postgraduate students in China cannot be generalized to other contexts; secondly, the classroom observation method applied in this study serves only for better conducting the stimulated recall interview. There was actually a lack of observational data on how each participant behave in each class. Future research can thus continue to explore online classroom silence through qualitative methods supported by quantitative data. 


\section{References}

Armstrong, P. (2007, July). Cultures of silence: Giving voice to marginalized communities. Paper presented at the meeting of the Standing Conference on University Research and Teaching in the Education of Adults, Belfast, Northern Ireland. Abstract retrieved from http://www.leeds.ac.uk/educol/documents/163812.htm

Beaudoin, M. F. (2002). Learning or lurking? Tracking the "invisible" online student. The internet and higher education, 5(2), 147-155. https://doi.org/10.1016/S1096-7516(02)00086-6

Benfield, G. (2000). Teaching on the web: Exploring the meanings of silence. Retrieved from http://pandora.nla.gov.au/pan/10088/20010816-0000/ultibase.rmit.edu.au/Articles/online/benfield1.htm

Bista, K. (2012). Silence in teaching and learning: Perspectives of a Nepalese graduate student. College Teaching, 60(2), 76-82. https://doi.org/10.1080/87567555.2011.633943

Carson, J. G., \& Nelson, G. L. (1996). Chinese students' perceptions of ESL peer response group interaction. Journal of second language writing, 5(1), 1-19. https://doi.org/10.1016/S1060-3743(96)90012-0

Chaudron, C. (1998). Second Language Classroom. Cambridge: Cambridge University Press.

Conrad, D. (2002). Inhibition, integrity and etiquette among online learners: The art of niceness. Distance Education, 23(2), 197-212. https://doi.org/10.1080/0158791022000009204

Daisley, M. (1996). An ethnographic study of silence in computer-mediated communication. Retrieved from http://wac.colostate.edu/rhetnet/daisley.html

Feenberg, A. (2001). Critical theory of technology. Oxford: Oxford University Press.

Harumi, S. (2010). Classroom silence: Voices from Japanese EFL learners. English Language Teaching Journal, 65(1), 1-10. https://doi.org/10.1093/elt/ccq046

Howard, J. R., \& Henney, A. L. (1998). Student participation and instructor gender in the mixed-age college classroom. The Journal of Higher Education, 69(4), 384-405. https://doi.org/10.1080/00221546.1998.11775141

Hu, Y., \& Fell-Eisentkraft, S. (2003). Immigrant Chinese students' use of silence in the language arts classroom: Perceptions, reflections and Actions. Teaching and Learning, 17(2), 55-63.

Jackson, J. (2002). Reticence in second language case discussion: Anxiety and aspiration. System, 30, 65-84. https://doi.org/10.1016/S0346-251X(01)00051-3

Jaworski, A. (2005). Introduction: Silence in institutional and intercultural contexts. Multilingua, 24, 1-6. https://doi.org/10.1515/mult.24.1-2.1

Jaworski, A., \& Sachdev, I. (1998). Beliefs about silence in the classroom. Language \& Education, 12(4), $273-292$. https://doi.org/10.1080/09500789808666754

Jin, L., \& Cortazzi, M. (2006). Changing practices in Chinese cultures of learning. Language, culture and curriculum, 19(1), 520. https://doi.org/10.1080/07908310608668751

Jones, J. F. (1999). From silence to talk: Cross-cultural ideas on students' participation in academic group discussion. English for Specific Purposes, 18(3), 243-259. https://doi.org/10.1016/S0889-4906(97)00059-8

Kalman, Y. M. (2008). Silence in online education: The invisible component. In Y. Eshet-Alkalai, A. Caspi, \& N. Geri (Eds.), Proceedings of the Chais conference on instructional technologies research: Learning in the technological era(pp.53-58). Israel: The Open University.

King, J. (2013). Silence in the second language classrooms of Japanese universities. Applied Linguistics, 34(3), $325-43$. https://doi.org/10.1093/applin/ams043

Kirkbride, P. S., Tang, S. F., \& Westwood, R. I. (1991). Chinese conflict preferences and negotiating behaviour: Cultural and psychological influences. Organization studies, 12(3), 365-386. https://doi.org/10.1177/017084069101200302

Li, W. Q., \& Wang, Y. S. (2018). A qualitative research on influencing factors of college students' classroom silence. Review of Higher Education, 46(3), 60-72.

Lickerman, A. (2009). The effective Use of Silence. Retrieved from http://www.psychologytoday.com/print/35809

Liu, J. (2001). Asian students' classroom communication patterns in U.S. universities: An emic perspective. Westport, CT: Ablex Publishing House.

Liu, N., \& Littlewood, W. (1997). Why do many students appear reluctant to participate in classroom learning discourse? System 25(3), 371-384. https://doi.org/10.1016/S0346-251X(97)00029-8 
Liu, X. Q. (2005). On classroom silence (Unpublished master's thesis). QuFu Normal University, Shangdong, China.

Pang, X. F. (2010). On college students' silence in EFL classroom (Unpublished master's thesis). ShanDong University, Shandong, China.

Ping, W. (2010). A case study of an in-class silent postgraduate Chinese student in London Metropolitan University: A journey of learning. TESOL Journal, 2, 207-214.

$\mathrm{Pu}$, C. H. (2009). Daxue yingyu ketang jiaoxue chenmo xianxiang fenxi ji jiaoxue jianyi. Nanchang gaozhuan xuebao, 24(4), 120-120. https://doi.org/10.3969/j.issn.1008-7354.2009.04.050

Qiao, C. H. (2008). On student's silence in EFL classroom context (Unpublished master's thesis). ChongQing Normal University, Chongqing, China.

Rachel, Z., Y., Knoke, D., \& Sakamoto, I. (2005). Rethinking silence in the classroom: Chinese students' experiences of sharing indigenous knowledge. International Journal of Inclusive Education, 9(3), $287-311$. https://doi.org/10.1080/13603110500075180

Spizzica, M. (1997). Cultural differences within "Western" and "Eastern" education. In Z. Golebiowski \& H. Borland (Eds.), Academic communication across disciplines and cultures (pp. 248-257). Melbourne: Victoria University of Technology.

Teng, M. L. (2009). Daxuesheng ketang chenmo de jiaoshi yinsu. Heilongjiang gao jiao yan jiu, 4, $146-148$. https://doi.org/10.3969/j.issn.1003-2614.2009.04.047

Tsui, A. B. (1996). Reticence and Anxiety in Second Language Learning. Voices From the Language Classroom, 2(4), 145-167. http://hdl.handle.net/10722/72267

Wen, W. P., \& Clement, R. (2010). A Chinese conceptualisation of willingness to communicate in ESL. Language Culture and Curriculum, 16(1), 18-38. https://doi.org/10.1080/07908310308666654

$\mathrm{Wu}, \mathrm{H}$. (2019). Reticence in the EFL classroom: voices from students in a Chinese university. International Journal of Applied Linguistics and English Literature, 8(6), 114-125. https://doi.org/10.7575/aiac.ijalel.v.8n.6p.114

Zembylas, M., \& Vrasidas, C. (2005). Levinas, the inter-face and the ethical challenge of pedagogy in online education. Educational Theory, 55(1), 61-78. https://doi.org/10.1111/j.1741-5446.2005.0005a.x

\section{Copyrights}

Copyright for this article is retained by the author(s), with first publication rights granted to the journal.

This is an open-access article distributed under the terms and conditions of the Creative Commons Attribution license which permits unrestricted use, distribution, and reproduction in any medium, provided the original work is properly cited. 